\title{
Anatomical Variation and Morphometric Study on Foramen Transversarium of the Upper Cervical Vertebrae in the Thai Population
}

\author{
Arada Chaiyamoon ${ }^{1}$, Supataechasit Yannasithinon ${ }^{1}$, Surachai Sae-Jung ${ }^{2}$, \\ Rarinthorn Samrid ${ }^{1}$, Tipsuda Thongbuakaew ${ }^{3}$, Sitthichai Iamsaard ${ }^{1,4}$ \\ ${ }^{1}$ Department of Anatomy, Faculty of Medicine, Khon Kaen University, Khon Kaen, Thailand \\ ${ }^{2}$ Department of Orthopaedics, Faculty of Medicine, Khon Kaen University, Khon Kaen, Thailand \\ ${ }^{3}$ Department of Medical Science, School of Medicine, Walailak University, Nakhon Si Thammarat, Thailand \\ ${ }^{4}$ Research Institute for Human High Performance and Health Promotion, Khon Kaen University, Khon Kaen, Thailand
}

\begin{abstract}
Study Design: Foramen transversarium (FT) and foramen arcuale (FA) of upper cervical vertebrae (C1 and C2) in the Thai population were investigated for variation and morphometry.

Purpose: This study aimed to reveal the morphometry of FT and FA in the Thai population.

Overview of Literature: The FT and FA are structures found in the upper spine that support the vertebral neurovascular system. Clinically, the surgical approaches to achieve upper cervical stability can be affected by spine variations. FT and FA morphometries have been documented to vary by nationality. However, such reports have been limited in the Thai population.

Methods: The FT and FA of dried C1 and C2 vertebrae (identified bones; $n=107$, males=53 and females=54) were observed and measured using a Digital Vernier Caliper (Mitutoyo, Kawasaki, Japan). Anteroposterior (AP) and transverse diameters of the left and right FTs ( $n=214$ ) were measured and compared between sexes. Variations and types of FT and FA found on the upper vertebrae were recorded and classified.

Results: The FT shape of the Thai C1 was AP elliptical, while of that of C2 was transverse elliptical. Compared to females, both diameters of the upper spine were significantly greater in males except for the AP diameter of $\mathrm{C} 2$ on the right side. All diameters were significantly different in both sexes and sides except for the AP diameter of $\mathrm{C} 1$ and $\mathrm{C} 2$. A common type of FT classified in $\mathrm{C} 1$ was type 2 (male [69.81\%], female [79.63\%]) whereas for C2 it was type 1 (male [63.21\%], female [59.26\%]). Moreover, an incomplete osseous bridge was a major FA subtype observed in the Thai spine.

Conclusions: FT morphometry has an elliptical shape and diameters are greater in males. The FT and FA variations identified in this study will be useful for surgeons treating vertebral neurovascular injuries of the posterior upper cervical spine in the Thai population.
\end{abstract}

Keywords: Cervical upper spine; Foramen transversarium; Foramen arcuale; Variation; Classification

Received Jul 31, 2020; Revised Sep 7, 2020; Accepted Sep 13, 2020

Corresponding author: Arada Chaiyamoon

Department of Anatomy, Faculty of Medicine, Khon Kaen University, Mitraparp Road, Khon Kaen, 40002, Thailand

Tel: +66-4336-3212, Fax: +66-4336-3212, E-mail: aradch@kku.ac.th 


\section{Introduction}

Foramen transversarium (FT) is the special foramen located on the left and right transverse processes of the cervical vertebrae ( $\mathrm{C} 1$ to $\mathrm{C} 7)$ containing the vertebral vessels and sympathetic plexus. Each side of the vertebral artery originates from the subclavian artery before continuing onto the FT of the 6th or 7th cervical vertebrae through the atlas to form the basilar artery on the brain stem. Clinically, the variable morphology and pathology of the FT are important to consider when performing surgery for screw fixation of the upper or lower cervical spine. In addition, variations of FT could be associated with compression of vertebral vessels, resulting in blood flow disturbances, especially vertebrobasilar insufficiency [1-3]. It has been reported that the anatomy and morphometry of FT vary by nationality [4-7]. Taitz et al. [7] in 1978 have classified the FT into five types based on the shape and direction of the main diameters. When comparing upper cervical vertebrae ( $\mathrm{C} 1$ and $\mathrm{C} 2$ ), the type 1 (round FT shape) with a greater diameter of the left $\mathrm{C} 2$ has been reported in Chilean [6] and Indian [7] populations. In contrast, the shape of the FT has been classified into 13 types in the South African population and no difference was found in the anteroposterior (AP) and transverse diameters of the upper cervical spine FTs [5]. In Kenyans, the shape of the FT most commonly found was type 2 or elliptical, with the main diameter in the AP direction [8]. Moreover, the incidence of a double FT has also been documented in various nationalities [1,7-10]. Particularly on $\mathrm{C} 1$, the presence of an osseous prominence in place of the $\mathrm{C} 1$ sulcus, known as a foramen arcuale (FA), has been investigated and is suggested to have clinical significance, especially in terms of potential instability of screw insertion at the atlantoaxial joint [11]. Recently, there was a report on the direct measurement of subaxial cervical pedicles in Thai patients [12]. However, the morphometry of FT and FA in the northeast Thai population has not yet been investigated. Therefore, this study aimed to investigate the morphometry and incidence of FT. In addition, the variant formation of FA was also recorded. This morphometric study explored the size of the FT for consideration prior to upper cervical spine fixation in the Thai population, with the aim of avoiding injury to vertebral vessels and the sympathetic plexus.

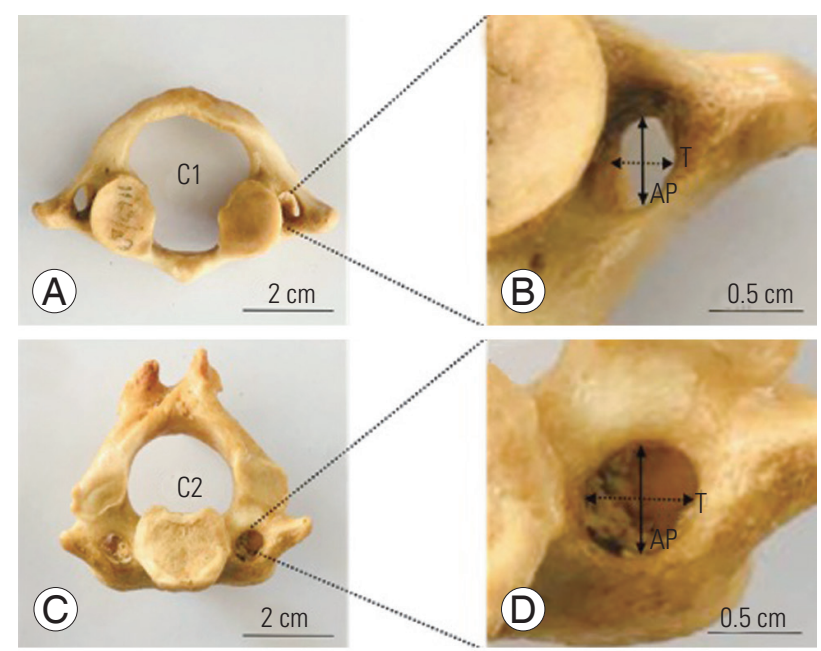

Fig. 1. Showing inferior view of upper cervical spines $(\mathbf{A}, \mathbf{C})$ and measurement of foramen transversarium diameters (B, D). C1, atlas; C2, axis AP; AP, anteroposterior dimeter; $\mathrm{T}$, transverse dimeter.

\section{Materials and Methods}

\section{Source of dried upper cervical spine samples}

For this study, upper cervical (C) spine vertebrae, atlas (C1) and axis (C2) without degenerative disorders were collected from 107 northeastern Thai skeletons (age, 37-94 years: average, 63 years; 53 males and 54 females) in the Unit of Human Bone Warehouse for Research, Department of Anatomy, Faculty of Medicine, Khon Kaen University, Thailand. This study was approved from the Ethics Committee for Human Research, Khon Kaen University, Thailand (approval no., HE621190).

The bones used in this retrospective study have been donated by people before their death with informed consents for studying and research of our medical and paramedical students.

\section{Measurement of foramen transversarium diameters}

The FT diameters of each upper spine on both sides were measured in the AP and transverse planes using a Digital Vernier Caliper (0.01 mm precision; Mitutoyo, Kawasaki, Japan) in triplicate as shown in Fig. 1. This measurement was performed by internal and external observers on different days. 
Table 1. The overall morphometry of foramen transversarium of upper cervical spine (C1 and C2)

\begin{tabular}{|c|c|c|c|c|c|c|c|c|}
\hline \multirow{3}{*}{ Sex } & \multicolumn{4}{|c|}{$\mathrm{C} 1$ (mm) } & \multicolumn{4}{|c|}{$\mathrm{C} 2(\mathrm{~mm})$} \\
\hline & \multicolumn{2}{|c|}{ AP } & \multicolumn{2}{|c|}{$\mathrm{T}$} & \multicolumn{2}{|c|}{$\mathrm{AP}$} & \multicolumn{2}{|c|}{$\mathrm{T}$} \\
\hline & Left & Right & Left & Right & Left & Right & Left & Right \\
\hline \multicolumn{9}{|l|}{ Male } \\
\hline Mean $\pm S D$ & $6.91 \pm 0.88$ & $7.03 \pm 0.97$ & $5.42 \pm 0.66$ & $5.72 \pm 0.79$ & $5.80 \pm 0.66$ & $5.68 \pm 0.71$ & $6.45 \pm 0.86$ & $6.25 \pm 0.86$ \\
\hline Range & $4.69-8.94$ & $3.41-8.96$ & $4.23-7.67$ & $2.89-7.96$ & $4.63-7.54$ & $3.83-7.55$ & $4.78-9.64$ & $5.24-9.55$ \\
\hline \multicolumn{9}{|l|}{ Female } \\
\hline Mean $\pm S D$ & $6.67 \pm 0.86$ & $6.95 \pm 0.82$ & $5.23 \pm 0.68$ & $5.32 \pm 0.66$ & $5.60 \pm 0.78$ & $5.75 \pm 0.78$ & $6.31 \pm 0.98$ & $5.82 \pm 0.87$ \\
\hline Range & $4.74-8.57$ & $5.48-9.66$ & $3.77-7.16$ & $3.62-7.07$ & $3.32-6.95$ & $4.29-7.65$ & $3.70-8.72$ & $4.29-7.71$ \\
\hline
\end{tabular}

$\mathrm{AP}$, anteroposterior; $\mathrm{T}$, transverse; SD, standard deviation.

Table 2. Morphological measurement difference between sexes and sides of foramen transversarium of upper cervical spine (C1 and C2)

\begin{tabular}{|c|c|c|c|c|c|c|c|c|c|c|c|c|}
\hline \multirow[b]{2}{*}{ Dimeter } & \multicolumn{3}{|c|}{ C1 (mm) } & \multicolumn{3}{|c|}{ C2 (mm) } & \multicolumn{3}{|c|}{$\mathrm{C} 1(\mathrm{~mm})$} & \multicolumn{3}{|c|}{$\mathrm{C} 2(\mathrm{~mm})$} \\
\hline & $\begin{array}{c}\text { Male } \\
(n=106)\end{array}$ & $\begin{array}{l}\text { Female } \\
(n=108)\end{array}$ & $p$-value & $\begin{array}{c}\text { Male } \\
(n=106)\end{array}$ & $\begin{array}{l}\text { Female } \\
(\mathrm{n}=108)\end{array}$ & $p$-value & $\begin{array}{c}\text { Left } \\
(\mathrm{n}=107)\end{array}$ & $\begin{array}{c}\text { Right } \\
(n=107)\end{array}$ & $p$-value & $\begin{array}{c}\text { Left } \\
(n=107)\end{array}$ & $\begin{array}{c}\text { Right } \\
(n=107)\end{array}$ & $p$-value \\
\hline Anteroposterior & & & 0.177 & & & 0.489 & & & $0.027^{*}$ & & & 0.856 \\
\hline Mean \pm SD & $6.97 \pm 0.92$ & $6.81 \pm 0.85$ & & $5.75 \pm 0.69$ & $5.68 \pm 0.76$ & & $6.79 \pm 0.87$ & $6.99 \pm 0.89$ & & $5.70 \pm 0.70$ & $5.72 \pm 0.74$ & \\
\hline Range & $3.41-8.96$ & $4.74-9.66$ & & $3.83-7.55$ & $3.32-7.65$ & & $4.69-8.94$ & $3.41-9.66$ & & $3.32-7.54$ & $3.83-7.65$ & \\
\hline Transverse & & & $0.003^{*}$ & & & $0.021^{*}$ & & & $0.016^{*}$ & & & $0.004^{*}$ \\
\hline Mean $\pm S D$ & $5.57 \pm 0.74$ & $5.28 \pm 0.67$ & & $6.36 \pm 0.88$ & $6.06 \pm 0.95$ & & $5.32 \pm 0.67$ & $5.52 \pm 0.75$ & & $6.38 \pm 0.93$ & $6.04 \pm 0.89$ & \\
\hline Range & $2.89-7.96$ & $3.62-7.16$ & & 4.78-9.64 & $3.70-8.72$ & & $3.37-7.67$ & $2.89-7.96$ & & $3.70-9.64$ & $4.29-9.55$ & \\
\hline$p$-value & $<0.000^{*}$ & $<0.000^{*}$ & & $<0.000^{*}$ & $<0.000^{*}$ & & $<0.000^{*}$ & $<0.000^{*}$ & & $<0.000^{*}$ & $<0.000^{*}$ & \\
\hline
\end{tabular}

SD, standard deviation.

" $p<0.05$ is statistically significant.

\section{Classification and observation of the foramen trans- versarium}

Morphological features of the FT were classified into five types including round (type 1), elliptical with AP (type 2), elliptical with transverse (type 3), elliptical with oblique from right to left (type 4), and elliptical with oblique from left to right (type 5) as described in previous reports [47]. In addition, the variations of the accessory FT on the left or right sides of the upper spine in both sexes were also recorded and photographed. In detail, the FT variations in both sexes were classified into five types; variant FAs of $\mathrm{C} 1$, trilateral accessory foramen transversarium (TFT), bilateral accessory foramen transversarium (BFT), unilateral accessory foramen transversarium (UFT), and hypoplasic foramen transversarium (HFT). Subtypes of FAs included bilateral complete foramen arcuale (BCFA), unilateral complete foramen arcuale (UCFA), and incomplete osseous bridge (IOB).

\section{Statistical analysis}

The mean and standard deviation from all morphometric measurements are presented in this study. These continuous variables were tested for their normality using the Shapiro-Wilk test. An independent sample $t$-test was used to test the mean differences between the sexes. A paired sample $t$-test was performed to test the mean differences between the left and right sides or between the AP and transverse diameters. Statistical significance was set at $p>0.05$. All data were analyzed using IBM SPSS ver. 20.0 (IBM Corp., Armonk, NY, USA). 


\section{Results}

\section{Morphometry of foramen transversarium of the upper cervical spine}

The overall morphometries (AP and transverse diameters) of the FT of the $\mathrm{C} 1$ and $\mathrm{C} 2$ in both sexes with the left and right sides of 107 dried bones are shown in Table 1.

\section{Comparison of foramen transversarium diameters between sexes and sides}

It was found that the transverse diameter of upper spine FTs in males was significantly greater than those of females (Table 2). The AP diameter of the $\mathrm{C} 1$ in both sexes was significantly greater than that of the transverse diameter, but there was no difference between males and females (Table 2). For C2, the transverse diameter of both sexes was significantly greater than that of AP. Additionally, AP and transverse diameters of the right FT in $\mathrm{C} 1$ were significantly greater than that of the left FT (Table 2). In contrast to $\mathrm{C} 1$, the transverse diameter of the right FT in C2 was significantly smaller compared with the left FT. However, there was no difference in AP diameters between the sides of C2 (Table 2). Moreover, the AP diameter of both sides in $\mathrm{C} 1$ was greater than that of transverse, while this measurement was significantly shorter than the transverse diameter of $\mathrm{C} 2$, as shown in Table 2. The two diameters of the $\mathrm{C} 1$ and C2 FTs were not significantly different between males and females, except for the

Table 3. Morphological measurement difference of sexes in left and right sides of foramen transversarium of upper cervical spine (C1 and C2)

\begin{tabular}{|c|c|c|c|c|c|c|}
\hline \multirow{2}{*}{ Dimension } & \multicolumn{3}{|c|}{$\mathrm{C} 1(\mathrm{~mm})$} & \multicolumn{3}{|c|}{$\mathrm{C} 2(\mathrm{~mm})$} \\
\hline & Male & Female & $p$-value & Male & Female & $p$-value \\
\hline AP-left & & & 0.150 & & & 0.167 \\
\hline Mean $\pm S D$ & $6.91 \pm 0.88$ & $6.67 \pm 0.86$ & & $5.80 \pm 0.66$ & $5.60 \pm 0.73$ & \\
\hline Range & $4.69-8.94$ & $4.740-8.57$ & & $4.63-7.54$ & $3.32-6.95$ & \\
\hline AP-right & & & 0.696 & & & 0.661 \\
\hline Mean $\pm S D$ & $7.04 \pm 0.97$ & $6.95 \pm 0.82$ & & $5.68 \pm 0.71$ & $5.75 \pm 0.78$ & \\
\hline Range & $3.41-8.96$ & $5.48-9.66$ & & $3.83-7.55$ & $4.29-7.65$ & \\
\hline$p$-value & 0.347 & $0.030^{*}$ & & 0.396 & 0.306 & \\
\hline T-left & & & 0.164 & & & 0.501 \\
\hline Mean $\pm S D$ & $5.42 \pm 0.66$ & $5.23 \pm 0.68$ & & $6.46 \pm 0.89$ & $6.31 \pm 0.98$ & \\
\hline Range & $4.23-7.67$ & $3.77-7.16$ & & $4.78-9.64$ & $3.70-8.72$ & \\
\hline T-right & & & $0.011^{*}$ & & & $0.018^{*}$ \\
\hline Mean $\pm S D$ & $5.72 \pm 0.79$ & $5.33 \pm 0.66$ & & $6.26 \pm 0.86$ & $5.82 \pm 0.87$ & \\
\hline Range & $2.89-7.96$ & $3.62-7.07$ & & $5.24-9.55$ & $4.29-7.71$ & \\
\hline$p$-value & $0.012^{*}$ & 0.389 & & 0.207 & $0.006^{*}$ & \\
\hline
\end{tabular}

AP, anteroposterior; T, transverse; SD, standard deviation.

" $p<0.05$ is statistically significant.

Table 4. Classification in various types of the foramen transversarium

\begin{tabular}{|c|c|c|c|c|c|c|c|c|c|c|}
\hline \multirow{2}{*}{ Cervical vertebrae } & \multicolumn{5}{|c|}{ Male $(n=106)$} & \multicolumn{5}{|c|}{ Female $(n=108)$} \\
\hline & Type 1 & Type 2 & Type 3 & Type 4 & Type 5 & Type 1 & Type 2 & Type 3 & Type 4 & Type 5 \\
\hline $\mathrm{C1}$ & $23.58(25)$ & $69.81(74)$ & - & $2.83(3)$ & $3.77(4)$ & $20.37(22)$ & $79.63(86)$ & - & - & - \\
\hline $\mathrm{C} 2$ & $63.21(67)$ & - & $17.92(19)$ & $9.43(10)$ & $9.43(10)$ & $59.26(64)$ & $3.70(4)$ & $12.96(14)$ & $12.04(13)$ & $12.04(13)$ \\
\hline Total & $86.79(92)$ & $69.81(74)$ & $17.92(19)$ & $12.26(13)$ & $13.20(14)$ & $79.63(88)$ & $83.33(90)$ & $12.96(14)$ & $12.04(13)$ & $12.04(13)$ \\
\hline
\end{tabular}

Values are presented as \% (number) 
transverse diameter of the right side in males, which was greater than that of females (Table 3). The FT diameters of the upper spine were not different between sexes. In contrast, the transverse diameter of the right FT in $\mathrm{C} 1$ was significantly greater than that of the left side in males, whereas the diameter in $\mathrm{C} 2$ of females was significantly shorter on the right side, as shown in Table 3.

\section{Classification of upper cervical spine foramen trans- versarium types}

In terms of FT types, type 1 (88.79\%), type $2(69.81 \%)$, type $3(17.92 \%)$, type $4(12.26 \%)$, and type $5(13.20 \%)$ were found in males (Table 4). In females, there were
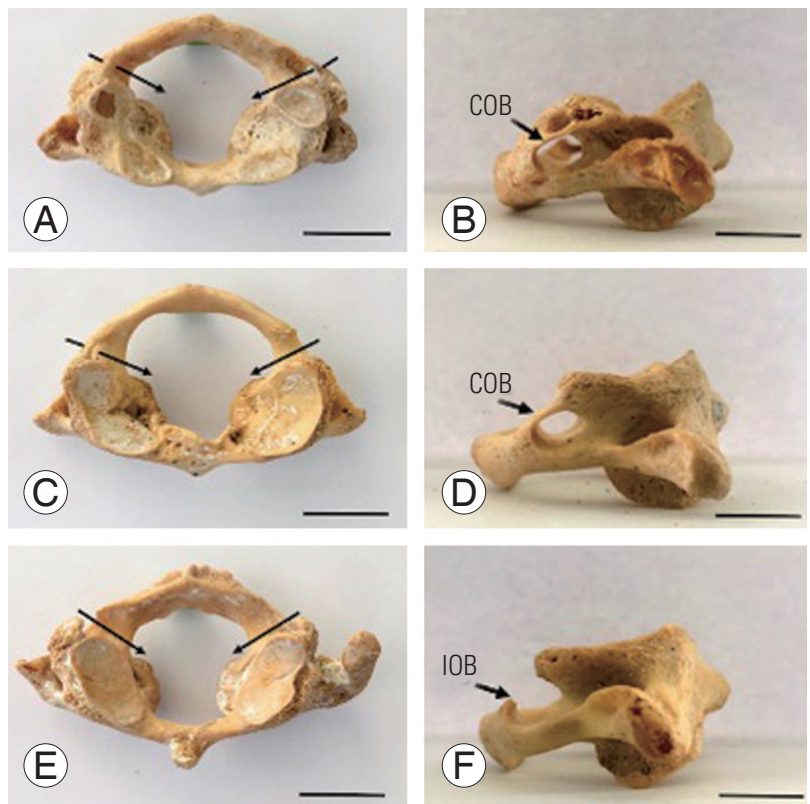

Fig. 2. Showing variations of foramen transversarium from $\mathrm{C} 1$ at superior $(\mathbf{A}-\mathbf{C})$ and lateral (D-F) views. (A, D) Showing bilateral complete FA on both sides of the posterior arch indicated by arrows. (B, E) Showing unilateral complete FA on either side of the posterior arch. (C, F) Showing IOB at the posterior arches indicated by short arrow. Scale bar=2 cm. FA, foramen arcuale; $\mathrm{COB}$, complete osseous bridge; IOB, incomplete osseous bridge. type $1(79.63 \%)$, type $2(83.33 \%)$, type $3(12.96 \%)$, type 4 (12.04\%), and type 5 (12.04\%), as shown in Table 4 . There was no incidence of type 3 in $\mathrm{C} 1$ or type 2 in $\mathrm{C} 2$ found in the male FTs. In the female FTs, types 3-5 in C1 were not observed (Table 4).

\section{Variations of foramen transversarium and foramen arcuale formation}

Classification and variations of FT are shown in Figs. 2 and 3. The incidence of BCFA was $0.93 \%$, while that of UCFA and IOB was $2.80 \%$ and $9.35 \%$, respectively. In addition, the TFT (1.87\%), BFT (25.23\%), UFT (8.41\%), and HFT found in males $(0.93 \%)$ were observed in C1. For C2, the incidence of UFT or HFT was $0.93 \%$.

\section{Discussion}

Previous studies have reported on FT morphology, including variations in size and shape. Clinically, varia-
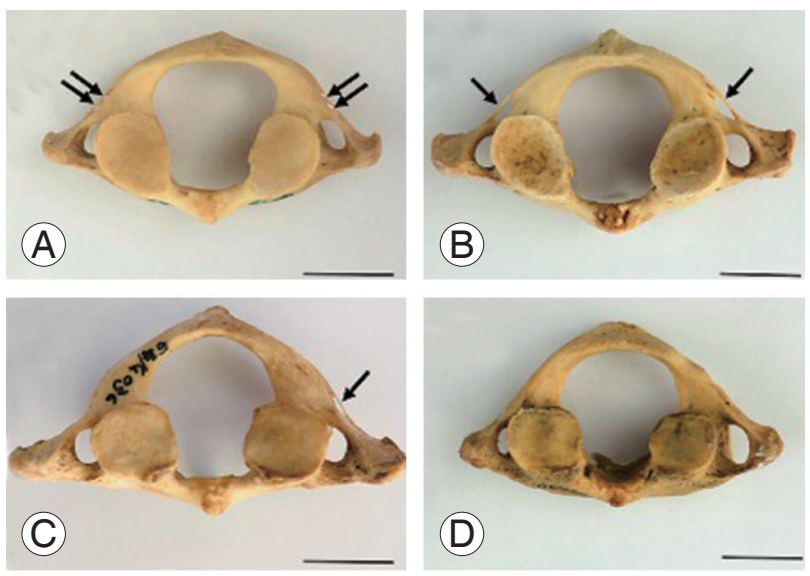

Fig. 3. Inferior view showing representative variations of FT in C1. (A) Trilateral accessory FT. (B) Bilateral accessory FT. (C) Unilateral accessory FT. (D) Hypoplasic FT. Arrows indicated accessory foramens. Scale bar=2 cm. FT, foramen transversarium.
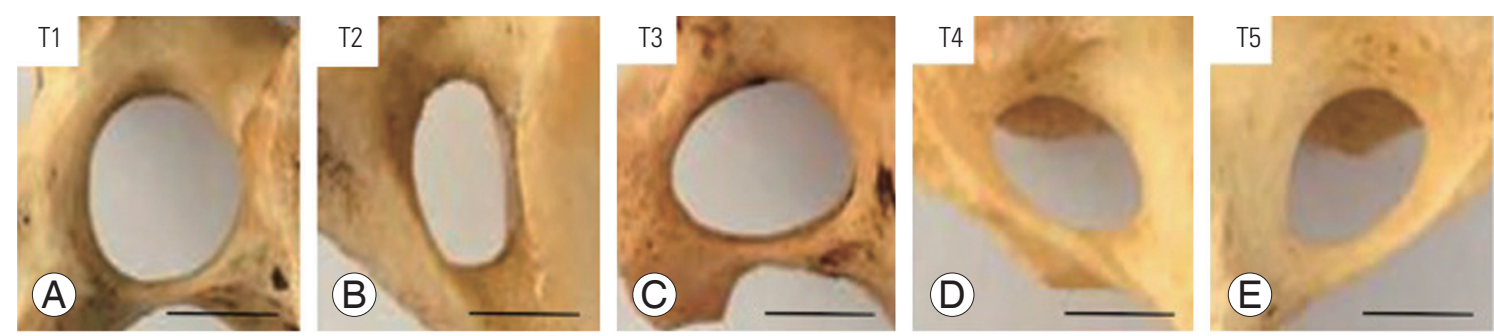

Fig. 4. (A-E) Classification of the foramen transversarium investigated in this study. T1, type 1 (round); T2, type 2 (elliptical with anteroposterior); T3, type 3 (elliptical with transverse); T4, type 4 (elliptical with oblique from right); T5, type 5 (elliptical with oblique from left). Scale bar=0.5 cm. 


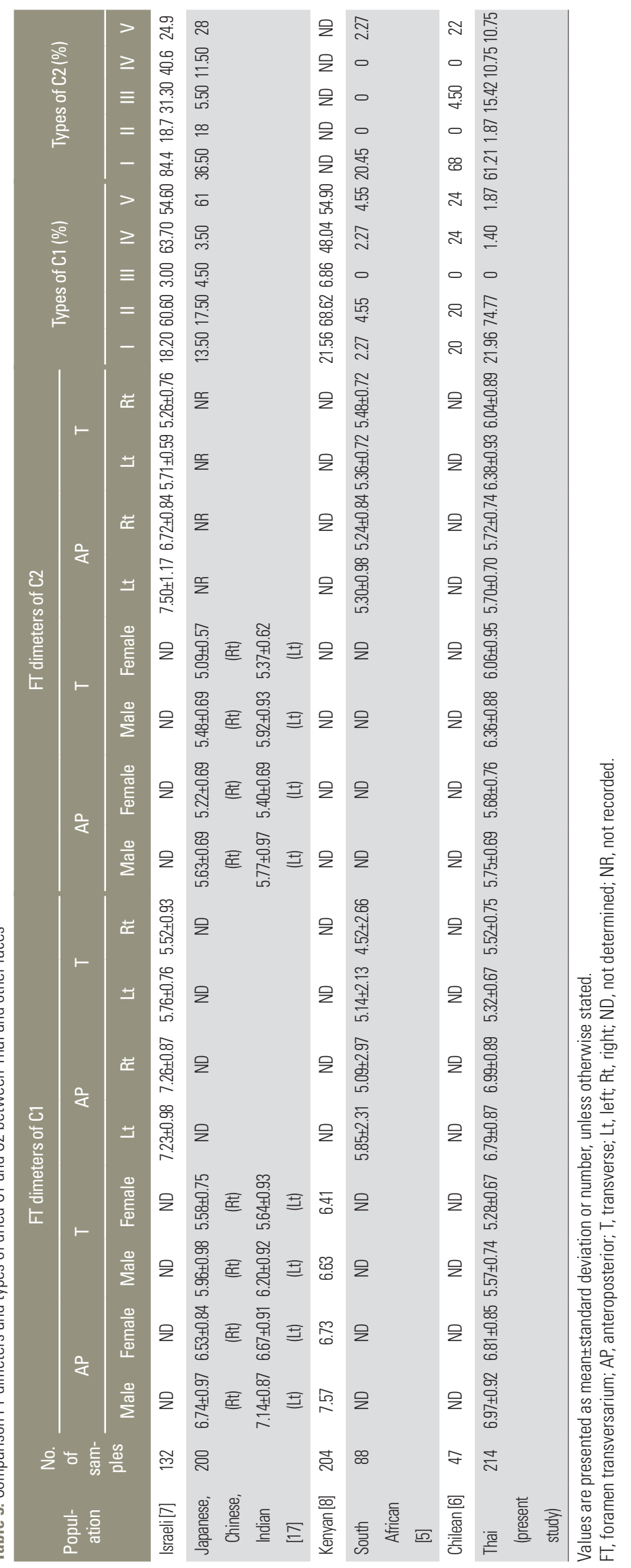


tions of FT could cause vertebral compression, leading to neurological symptoms. Additionally, these variations are important for surgeons and radiologists to consider prior to surgery on the posterior upper cervical spine [13]. The morphometric alterations of FT diameters have been documented in many populations including Chilean [6], Kenyan [8], Greek [4], Indian [7,14], American [15], Turkish [16], Japanese [17], Chinese [17], and Korean [18]. We herein observed the shape and size of the FT in Thais for the first time. Using Digital Vernier Caliper (Mitutoyo), our results showed shorter FT diameters in both sides of the upper cervical spine compared with Chilean and Kenyan populations $[6,8]$. The transverse diameter of the male $\mathrm{C} 1$ observed in one recent study was significantly greater than that of females, unlike what was found for Kenyans [8], which showed AP diameters in males that were significantly greater than in females. Similar to Asian populations [17], transverse diameters in Thais were significantly greater in males than in females. However, the transverse diameter in Kenyans was not different between sexes, whereas its diameter was greater in Thai males. In South Africans, no difference in FT diameters of the upper spine vertebrae have been found [5]. In general, the transverse diameter of the left side is greater than that of the right side in some nationalities including the Thai population [5-7], as summarized in Table 5. In the literature, the shape of the FT can be classified into 5,12 , and 13 types $[5-8,17]$. The FTs in this study were classified into five types as shown in Fig. 4. We found that the type 2 FT in $\mathrm{C} 1$ is mostly investigated (male, $69.81 \%$; female, $79.63 \%$ ) which is similar to that of the Kenyan [8], South African [5], Japanese, Chinese, and Indian populations [17]. In contrast, mostly only type 4 in Israeli and types 4 and 5 in Chilean and South African populations were found, with equal incidence [5-7]. However, Kimura et al. [17] in 1985 reported that mostly type 5 was observed in the Japanese, Chinese, and Indian population. For $\mathrm{C} 2$, the most common type of FT found in Thailand was type 1 , which is similar to that reported in many countries [5-7,17]. In addition, the accessory FT (also called retrotransverse foramen) of $\mathrm{C} 1$ most commonly found in this study was BFT (25.23\%), which was higher than that found in the Romanian (1.41\%) [19], South AfricanSpanish (1.5\%) [20], Greek (1.61\%) [21], Spanish (2.27\%) [22], Indian (4\%) [23], and Indian populations (4.08\%) [24]. The incidence of UFT was approximately $9.38 \%$, which was lower than that found in the Indian popula- tion (18\%) [23]. In contrast, this incidence was higher in South Africa-Spanish (5.8\%) [20]. Furthermore, the presence of TFT and HFT in C1 from our study was $1.86 \%$, which has not been reported previously. The finding of HFT in both $\mathrm{C} 1$ and $\mathrm{C} 2(1.86 \%)$ agreed with that found in C6 (1.1\%) of the Italian population [25]. Moreover, the incidence of FA, sulcus or retroarticular canal for the vertebral artery, was found to be highest in the IOB subtype (9.35\%). However, the highest incidences of UCFA were reported in the northern Greek (24.43\%) [26] and Turkish populations ( $15.38 \%$ and $10 \%$, respectively) $[16,27]$. The incidence of the FA subtype (BCFA) observed in the Thai population was $0.93 \%$, which was low and comparable with that of the northern Greek (1.13\%) [26] and Turkish (1.6\%) populations [27]. In contrast, Cirpan et al. [16] in 2017 reported that BCFA had not been investigated in the Turkish population.

\section{Conclusions}

The morphometry of the upper spine FT in the Thai population is unique and differs from that of other populations. We conclude that all morphometric parameters are greater in the male FT and transverse diameter of the right $\mathrm{C} 1$, except for $\mathrm{C} 2$, which is greater than the left $\mathrm{C} 2$ in both sexes. Additionally, the most common type of FT in $\mathrm{C} 1$ is type 2, whereas in $\mathrm{C} 2$ the most common type of FT is type 1. Moreover, BFT is the most common FT variation investigated in the Thai population. The knowledge of FT and FA variations can identify potential landmarks for surgeons, neurosurgeons, and radiologists to help determine the most accurate approaches prior to posterior upper cervical surgery for specific populations.

\section{Conflict of Interest}

No potential conflict of interest relevant to this article was reported.

\section{Acknowledgments}

We would like to thank the Unit of Human Bone Warehouse for Research, Department of Anatomy, Faculty of Medicine, Khon Kaen University, Thailand, to provide the upper cervical spine samples from donated and identified skeletons. 


\section{ORCID}

Arada Chaiyamoon: https://orcid.org/0000-0002-47489021; Supataechasit Yannasithinon: https://orcid.org/00000002-0385-3856; Surachai Sae-Jung: https://orcid. org/0000-0002-7133-1603; Rarinthorn Samrid: https:// orcid.org/0000-0001-8958-9162; Tipsuda Thongbuakaew: https://orcid.org/0000-0001-9643-8477; Sitthichai Iamsaard: https://orcid.org/0000-0002-6793-2879

\section{Author Contributions}

AC designed the study. SY, RS, and TT performed the bone measurement. SS performed data analysis and interpretation. AC and SI wrote the main draft and all authors contributed to critically revising the manuscript.

\section{References}

1. Kaya S, Yilmaz ND, Pusat S, Kural C, Kirik A, Izci Y. Double foramen transversarium variation in ancient Byzantine cervical vertebrae: preliminary report of an anthropological study. Turk Neurosurg 2011;21:5348.

2. Lamberty BG, Zivanovic S. The retro-articular vertebral artery ring of the atlas and its significance. Acta Anat (Basel) 1973;85:113-22.

3. Tubbs RS, Johnson PC, Shoja MM, Loukas M, Oakes WJ. Foramen arcuale: anatomical study and review of the literature. J Neurosurg Spine 2007;6:31-4.

4. Zibis AH, Mitrousias V, Baxevanidou K, Hantes M, Karachalios T, Arvanitis D. Anatomical variations of the foramen transversarium in cervical vertebrae: findings, review of the literature, and clinical significance during cervical spine surgery. Eur Spine J 2016;25:4132-9.

5. Abdul RS, Lazarus L, Rennie C, Satyapal KS. The foramen transversarium of typical and atypical cervical vertebrae: morphology and morphometry. Int J Morphol 2018;36:1439-46.

6. Guerra MM, Fuentes PR, Roa I. Anatomical variations of the foramen transversarium in cervical vertebrae. Int J Morphol 2017;35:719-22.

7. Taitz C, Nathan H, Arensburg B. Anatomical observations of the foramina transversaria. J Neurol Neurosurg Psychiatry 1978;41:170-6.

8. Karau PB, Odula P. Some anatomical and morpho- metric observations in the transverse foramina of the atlas among Kenyans. Anat J Afr 2013;2:61-6.

9. Nagar Y, Taitz C, Reich R. What can we make of these fragments?: excavation at 'Mamilla' cave, Byzantine period, Jerusalem. Int J Osteoarchaeol 1999;9:29-38.

10. Das S, Suri R, Kapur V. Double foramen transversaria: an osteological study with clinical implications. Int Med J 2005;12:311-3.

11. Pekala PA, Henry BM, Pekala JR, et al. Prevalence of foramen arcuale and its clinical significance: a meta-analysis of 55,985 subjects. J Neurosurg Spine 2017;27:276-90.

12. Mahiphot J, Iamsaard S, Sawatpanich T, Sae-Jung S, Khamanarong K. A morphometric study on subaxial cervical pedicles of Thai people. Spine (Phila Pa 1976) 2019;44:E579-84.

13. Bodon G, Grimm A, Hirt B, Seifarth H, Barsa P. Applied anatomy of screw placement via the posterior arch of the atlas and anatomy-based refinements of the technique. Eur J Orthop Surg Traumatol 2016;26:793-803.

14. Yadav Y, Goswami P, Bharihoke V. An osteological study of foramen trasversarium: variations and clinical aspects. J Evol Med Dent Sci 2014;3:14562-6.

15. Sangari SK, Dossous PM, Heineman T, Mtui EP. Dimensions and anatomical variants of the foramen transversarium of typical cervical vertebrae. Anat Res Int 2015;2015:391823.

16. Cirpan S, Yonguc GN, Edizer M, Mas NG, Magden AO. Foramen arcuale: a rare morphological variation located in atlas vertebrae. Surg Radiol Anat 2017;39:877-84.

17. Kimura K, Konishi M, Hu SY. Shape and size of the transverse foramina in Japanese. Okajimas Folia Anat Jpn 1985;62:123-31.

18. Malla HP, Kim SB, Won JS, Choi MK. Study of the transverse foramen in the subaxial cervical spine in Korean patients with degenerative changes: an anatomical note. Neurospine 2018;15:163-8.

19. Veleanu C, Barzu S, Panescu S, Udroiu C. The retrotransverse groove or canal of the atlas and its significance. Acta Anat 1977;97:400-2.

20. Sanchis-Gimeno JA, Blanco-Perez E, Perez-Bermejo M, Llido S, Nalla S. Retrotransverse foramen of the atlas: prevalence and bony variations. Eur Spine J 2018;27:1272-7.

21. Paraskevas GK, Tsitsopoulos PP, Ioannidis OM. 
Incidence and purpose of the clival canal, a "neglected" skull base canal. Acta Neurochir (Wien) 2013;155:139-40.

22. Quiles-Guinau L, Gomez-Cabrero A, Miquel-Feucht $\mathrm{M}$, Aparicio-Bellver L. Retrotransverse foramen in atlas vertebrae of the late 17 th and 18 th centuries. Ital J Anat Embryol 2016;121:123-32.

23. Patel NP, Gupta DS, Parmar ND. Incidence of ponticles in human atlas vertebrae: a study from South Gujarat population. Indian J Clin Anat Physiol 2015;2:135-9.

24. Gupta SC, Gupta CD, Arora AK, Maheshwari BB. The retrotransverse groove (canal) in the Indian atlas vertebrae. Anat Anz 1979;145:514-6.

25. Travan L, Saccheri P, Gregoraci G, Mardegan C, Crivellato E. Normal anatomy and anatomic variants of vascular foramens in the cervical vertebrae: a paleoosteological study and review of the literature. Anat Sci Int 2015;90:308-23.

26. Paraskevas G, Papaziogas B, Tsonidis C, Kapetanos G. Gross morphology of the bridges over the vertebral artery groove on the atlas. Surg Radiol Anat 2005;27:129-36.

27. Cakmak O, Gurdal E, Ekinci G, Yildiz E, Cavdar S. Arcuate foramen and its clinical significance. Saudi Med J 2005;26:1409-13. 